\title{
REDUCED COMPLEXITY QUASI-CYCLIC LDPC ENCODER FOR IEEE 802.11N
}

\author{
Monica Mankar ${ }^{1}$, Gajendra Asutkar ${ }^{2}$, Pravin Dakhole $^{3}$ \\ ${ }^{1}$ Research Scholar Department of Electronics Engineering, \\ Yeshwantrao Chavan college of Engineering., Nagpur, India. \\ ${ }^{2}$ Professor, Department of Electronics and communication Engineering, \\ Priyadarshani Institute of Engineering and technology Nagpur, India \\ ${ }^{3}$ Professor,Department of Electronics Engineering, \\ Yeshwantrao Chavan college of Engineering., Nagpur, India .
}

\begin{abstract}
In this paper, we present a low complexity Quasi-cyclic-low-density-parity-check (QC-LDPC) encoder hardware based on Richardson and Urbanke lower- triangular algorithm for IEEE 802.11n wireless LAN Standard for 648 block length and 1/2 code rate. The LDPC encoder hardware implementation works at $301.433 \mathrm{MHz}$ and it can process $12.12 \mathrm{Gbps}$ throughput. We apply the concept of multiplication by constant matrices in GF(2) due to which hardware required is also optimized. Proposed architecture of QC-LDPC encoder will be compatible for high-speed applications. This hardwired architecture is less complex as it avoids conventionally used block memories and cyclic-shifters.
\end{abstract}

\section{KEYWORDS}

Quasi-cyclic -low-density-parity-check (QC-LDPC), WLAN (IEEE802.11n), Richardson and Urbanke lower- triangular algorithm, encoder

\section{INTRODUCTION}

In recent years, Low -density parity -check codes [1], which were first proposed by R. Gallager in the early 1960's and rediscovered by MacKay and Neal [2], have received a lot of attention due to their remarkable error correction capabilities near Shannon's limit with advancements in VLSI. Many current and next generation communications standards such as WLAN (IEEE802.11n), Mobile WiMAX (IEEE802.16e), DVB-Sand, 10GBaseT (IEEE802.3an) have adopted or considering the use of LDPC codes In spite of the better performance and lower decoding complexity of LDPC codes, the major drawback of LDPC codes is it's high encoding complexity. Low complexity of the encoder can be achieved by using structured LDPC codes. Many encoding algorithms were used in the past, it is suggested that the encoding complexity can be significantly reduced by using an approximate upper triangular parity check matrix to construct LDPC codes.

In this work, we have adopted structured LDPC codes known as the Quasi-cyclic Low-density parity check codes. Quasi-Cyclic has been proposed to reduce the complexity of LDPC while obtaining the similar performances. In QC-LDPC codes, the parity check matrix is a sparse

DOI : $10.5121 /$ vlsic.2016.7604 
matrix as it consists of less no of one's but the generator matrix is not a sparse matrix. Hence, most commonly lower-triangular matrix algorithm is used to simplify the encoding methods as suggested in Richardson and Urbanke method [4]. The encoder based on Richardson and Urbanke algorithm [3] which provides effective linear running time for some codes with a sparse paritycheck matrix. The algorithm consists of two phases: preprocessing and encoding. To increase the encoding throughput, Parallel encoding and pipelining structures are applied. The encoding throughputs are determined by using encoding clock frequency and number of encoding iterations.

\section{LOW-DENSITY PARITY CHECK CODES}

LDPC codes are linear block codes that can be denoted as $(n, k)$ or (n, wc, wr), where $n$ is the length of the codeword, $\mathrm{k}$ is the length of the message bits, wc is the column weight (i.e. the number of nonzero elements in a column of the parity-check matrix), and wr is the row weight (i.e. the number of nonzero elements in a row of the parity-check matrix).

\subsection{Characteristics for LDPC codes}

LDPC codes are linear block codes that can be denoted as $(n, k)$ or (n, wc, wr), where $n$ is the length of the codeword, $\mathrm{k}$ is the length of the message bits, wc is the column weight (i.e. the number of nonzero elements in a column of the parity-check matrix), and wr is the row weight (i.e. the number of nonzero elements in a row of the parity-check matrix).

\subsubsection{Parity-check}

LDPC codes are represented by a parity-check matrix $\mathrm{H}$, where $\mathrm{H}$ represents a binary matrix that, must satisfy Equation 1.

$$
H x^{T}=0
$$

Where $\mathrm{x}$ is a codeword.

\subsubsection{Low-density}

$\mathrm{H}$ is a sparse matrix (i.e. the number of ' 1 's is much lower than the number of ' 0 's). It is the sparseness of $\mathrm{H}$ that guarantees the low computing complexity.

\subsection{Representation of LDPC codes}

Graphical representation of LDPC code is known as Tanner graph. Fig. 1. shows an example of $(12,6)$ LDPC code parity check matrix and its Tanner graph. Tanner graph consists of two sets of nodes, check nodes and variable nodes. Rows and columns of parity check matrix $\mathrm{H}$ can be mapped to check node units and variable node units. An edge between check node and the variable node is drawn only if there is ' 1 ' in the $\mathrm{H}$ matrix as in equation 2 . The connected nodes represent that the mutual information can be transmitted between check nodes and variable nodes. 


$$
\mathrm{H}=\left[\begin{array}{llllllllllll}
1 & 1 & 0 & 1 & 0 & 1 & 1 & 0 & 0 & 1 & 0 & 0 \\
1 & 1 & 1 & 1 & 1 & 0 & 0 & 0 & 0 & 0 & 1 & 0 \\
0 & 0 & 0 & 0 & 0 & 1 & 1 & 1 & 0 & 1 & 1 & 1 \\
1 & 0 & 1 & 0 & 0 & 0 & 0 & 1 & 1 & 0 & 1 & 1 \\
0 & 0 & 1 & 1 & 1 & 0 & 1 & 1 & 1 & 0 & 0 & 0 \\
0 & 1 & 0 & 0 & 1 & 1 & 0 & 0 & 1 & 1 & 0 & 1
\end{array}\right]
$$

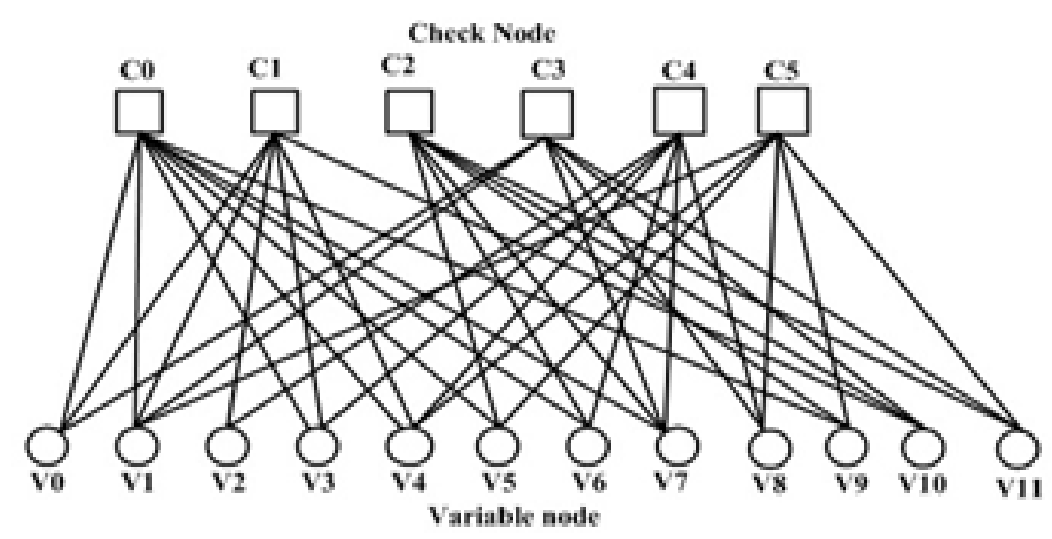

Figure 1. Tanner graph representation of Parity Check matrix $(12,6)$

\section{QC-LDPC CODE CHECK CODES FOR IEEE 802. 11N STANDARD}

Quasi-Cyclic LDPC (QC-LDPC) codes are structured LDPC codes come along with a more efficient implementation, while maintaining great performance. Quasi-cyclic codes are codes in which a cyclic shift of one codeword results in another codeword. Due to the cyclic structure, they require less memory as compared with the conventional LDPC codes. In addition, QCLDPC codes also show the high-speed decoding because of the sparseness of its parity check matrix [5]. In all recent wireless communication standards, such as IEEE 802.11n, IEEE 802.11ac, and IEEE 802.16e, the QC-LDPC codes are used as an error correction code [6]-[8].All these wireless communication standards support a very high data rate over hundreds of Mbps. These standards also support various code rates and block lengths. QC-LDPC codes adopted by IEEE $802.11 \mathrm{n} / \mathrm{ac}$ standards support four code rates, i.e., 1/2, 2/3, 3/4 and 5/6, and three block lengths, i.e., 648, 1296 and 1944 for a total of 12 possible codes as shown in Table 1. 
International Journal of VLSI design \& Communication Systems (VLSICS) Vol.7, No.5/6, December 2016

Table 1. Twelve LDPC codes for IEEE 802.11n Standard

\begin{tabular}{|c|c|c|c|c|c|c|}
\hline Codes & $\begin{array}{c}\text { No of } \\
\text { Columns } \\
(\boldsymbol{\rho})\end{array}$ & $\begin{array}{c}\text { No of } \\
\text { Rows } \\
(\gamma)\end{array}$ & $\begin{array}{c}\text { Code } \\
\text { rate } \\
(\mathbf{r})\end{array}$ & $\begin{array}{c}\text { Sub } \\
\text { matrix } \\
\text { size(z) }\end{array}$ & $\begin{array}{c}\text { Codeword } \\
\text { length(n) }\end{array}$ & $\begin{array}{c}\text { Information } \\
\text { Length(k) }\end{array}$ \\
\hline 1 & 24 & 12 & $1 / 2$ & 27 & 648 & 324 \\
\hline 2 & 24 & 12 & $1 / 2$ & 54 & 1296 & 648 \\
\hline 3 & 24 & 12 & $1 / 2$ & 81 & 1944 & 972 \\
\hline 4 & 24 & 8 & $2 / 3$ & 27 & 648 & 432 \\
\hline 5 & 24 & 8 & $2 / 3$ & 54 & 1296 & 864 \\
\hline 6 & 24 & 8 & $2 / 3$ & 81 & 1944 & 1296 \\
\hline 7 & 24 & 6 & $3 / 4$ & 27 & 648 & 486 \\
\hline 8 & 24 & 6 & $3 / 4$ & 54 & 1296 & 972 \\
\hline 9 & 24 & 6 & $3 / 4$ & 81 & 1944 & 1458 \\
\hline 10 & 24 & 4 & $5 / 6$ & 27 & 648 & 540 \\
\hline 11 & 24 & 4 & $5 / 6$ & 54 & 1296 & 1080 \\
\hline 12 & 24 & 4 & $5 / 6$ & 81 & 1944 & 1620 \\
\hline
\end{tabular}

In the IEEE $802.11 \mathrm{n}$ wireless standard involves three sub-blocks $(27,54$, and 81 bits) and four code rates $(1 / 2,2 / 3,3 / 4$, and 5/6). Each sub-block contains $\mathrm{Z} \times \mathrm{Z}$ sparse matrices. Before beginning the encoding process, the code check matrix must be expanded based on the sizes of sub-blocks [27]. According to all parameters expanded size of the matrix is given in Table 2.

Table 2. Expanded Matrix sizes corresponding to sub-block size

\begin{tabular}{|c|c|c|c|c|c|}
\hline \multicolumn{2}{|c|}{ Code rate } & $1 / 2$ & $2 / 3$ & $3 / 4$ & $5 / 6$ \\
\hline \multicolumn{2}{|c|}{ Matrix size } & $12 \times 24$ & $8 \times 24$ & $6 \times 24$ & $4 \times 24$ \\
\hline \multirow{3}{*}{$\begin{array}{c}\text { Expanded } \\
\text { Matrix size } \\
\text { correspondi } \\
\text { ng to sub } \\
\text { block size }\end{array}$} & $\begin{array}{c}\text { Sub-block } \\
27\end{array}$ & $324 \times 648$ & $216 \times 648$ & $162 \times 648$ & $108 \times 648$ \\
\hline & $\begin{array}{c}\text { Sub-block } \\
54\end{array}$ & $648 \times 1296$ & $432 \times 1296$ & $324 \times 1296$ & $216 \times 1296$ \\
\hline & $\begin{array}{c}\text { Sub-block } \\
81\end{array}$ & $972 \times 1944$ & $648 \times 1944$ & $486 \times 1944$ & $324 \times 1944$ \\
\hline
\end{tabular}

Fig. 2 represents the parity check matrix for code length 648 and code rate $1 / 2$. Each entry in the square represents a 27 by 27 square matrix, where 0 represents the identity matrix and the dash, '-', indicates a cyclic shift to the right of the identity matrix by a number of places equal to the entry given in a box. 
International Journal of VLSI design \& Communication Systems (VLSICS) Vol.7, No.5/6, December 2016

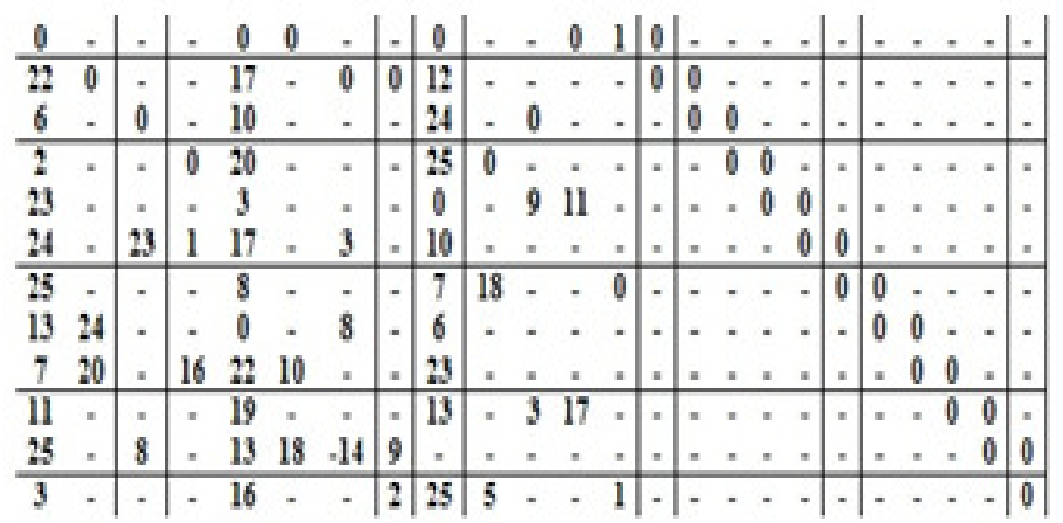

Figure 2. Basic Matrix for IEEE $802.11 \mathrm{n}$ for the rate $1 / 2$ and codeword length 648

LDPC encoder can be designed using the lower triangular matrix approximation, where the parity check matrix is converted into a lower triangular form by row and column permutations without changing its linearity [3]. To convert into a lower triangular form, the parity check matrix has been divided into sub matrices A, B, C, D, T, E has a certain order as shown in equation 3 . The encoding complexity is $\mathrm{O}(\mathrm{n}+\mathrm{g} 2)$, $\mathrm{g}$ is the row of matrix E. Figure 3 shows a standard lower triangular form of Parity Check Matrix obtained by performing certain column switching operations.

$$
H=\left[\begin{array}{lll}
A_{(m-g)^{*}(n-m)} & B_{(m-g)^{*}(g)} & T_{(m-g)^{*}(m-g)} \\
C_{z^{*}(z-m)} & D_{z^{*}} & \mathbf{E}_{z^{*}(m-z)}
\end{array}\right]
$$

Where $A$ is $(m-g) *(n-m), \quad B$ is $(m-g) * g, C$ is $g *(n-m), D$ is $g * g, E$ is $g *(m-g)$, $\mathrm{T}$ is $(\mathrm{m}-)^{*}(\mathrm{~m}-\mathrm{g}), \mathrm{T}$ is a proposed lower triangular matrix.

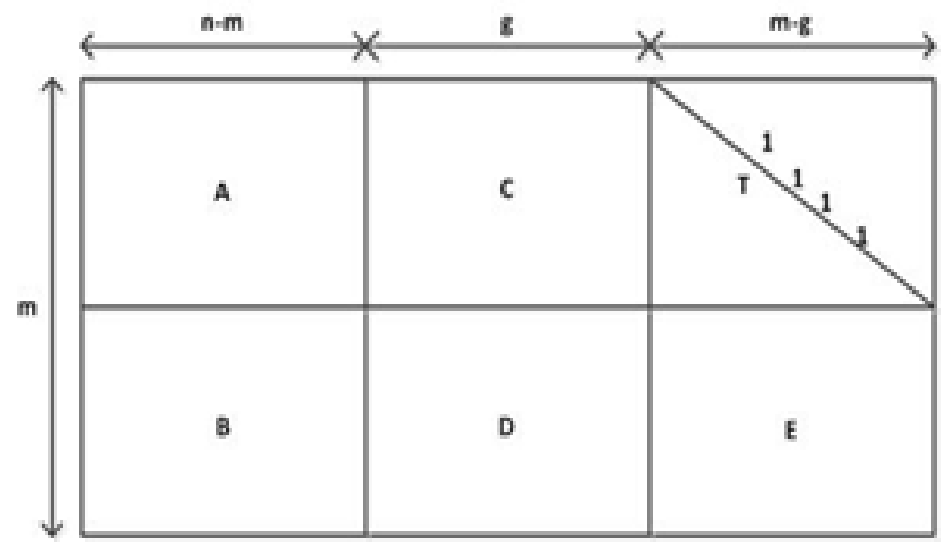

Figure 3. Lower Triangular Form of Parity Check Matrix 
International Journal of VLSI design \& Communication Systems (VLSICS) Vol.7, No.5/6, December 2016

\subsection{Richardson - Urbanke Encoding Method [3]}

\subsubsection{Pre-processing Step}

Input : Non Singular Parity Check Matrix 'H'

Output: To obtain an equivalent parity check matrix of the form such that $-E T^{-1} B+D$ is non singular.

Step 1: By performing row and column permutation to bring the parity-check matrix $H$ into an appropriate lower triangular form such as

$$
\mathbf{H}=\left[\begin{array}{lll}
\mathbf{A} & \mathbf{B} & \mathbf{T} \\
\mathbf{C} & \mathbf{D} & \mathbf{E}
\end{array}\right] \text { with a small gap g. }
$$

Step 2: Use of Gaussian Elimination to perform Pre- Multiplication.

$$
\left[\begin{array}{ll}
I & 0 \\
-E T^{-1} & I
\end{array}\right]\left[\begin{array}{lll}
A & B & T \\
C & D & E
\end{array}\right]=\left[\begin{array}{lll}
A & B & T \\
-E T^{-1} A+C & -E T^{-1} B+D & 0
\end{array}\right]
$$

To check whether $-E T^{-1} B+D$ is non singular. If necessary further column permutation can be used to achieve this property.

\subsubsection{Encoding Step}

Input: Parity-check matrix of the form $H=\left[\begin{array}{ccc}A & B & T \\ C & D & E\end{array}\right]$ such that $-E T^{-1} B+D$ is non singular.

Output: The vector $\mathrm{x}=\left(\mathrm{s}, \mathrm{p}_{1}, \mathrm{p}_{2}\right)$ such that $\mathrm{H} \mathrm{x}^{\mathrm{T}}=0$

$$
\left[\begin{array}{lll}
A & B & T \\
-E T^{-1} A+C & -E T^{-1} B+D & 0
\end{array}\right]\left[\begin{array}{l}
s \\
p 1 \\
p 2
\end{array}\right]=0
$$

Solving equation 5 we get following two equations

$$
\begin{gathered}
A s^{T}+B p 1^{T}+T p 2^{T} \\
\left(-E T^{-1} A+C\right) s^{T}+\left(-E T^{-1} B+D\right) p_{1}{ }^{T}=0
\end{gathered}
$$

Let $\phi=-E T^{-1} B+D$ which is non singular. From equation 6 and7, we get 
International Journal of VLSI design \& Communication Systems (VLSICS) Vol.7, No.5/6, December 2016

$$
\begin{aligned}
& p_{1}{ }^{T}=-\phi^{-1}\left(-E T^{-1} A+C\right) s^{T} \\
& p_{2}{ }^{T}=-T^{-1}\left(A s^{T}+B p_{1}{ }^{T}\right)
\end{aligned}
$$

The encoding process flow chart is shown Fig.4. The area complexity in the encoding process of LDPC codes is described in Table 3 [3].

\begin{tabular}{|c|c|c|}
\hline \multicolumn{3}{|c|}{ pl Complexity } \\
\hline Operation & Requirements & Complexity \\
\hline$A s^{T}$ & $(\mathrm{~m}-\mathrm{g})^{*}(\mathrm{n}-\mathrm{m})$ sparse multiplication & $\mathrm{O}(\mathrm{n})$ \\
\hline$T^{-1}\left[A s^{T}\right]$ & $(m-g)^{*}(m-g)$ back subtraction & $\mathrm{O}(\mathrm{n})$ \\
\hline$-E T^{-1}\left[A s^{T}\right]$ & $(\mathrm{g})^{*}(\mathrm{~m}-\mathrm{g})$ sparse multiplication & $\mathrm{O}(\mathrm{n})$ \\
\hline$C s^{T}$ & $(\mathrm{n}-\mathrm{m})^{*}(\mathrm{~g})$ sparse multiplication & $\mathrm{O}(\mathrm{n})$ \\
\hline$-E T^{-1}\left[A s^{T}\right]+C s^{T}$ & (n-m) bit addition & $\mathrm{O}(\mathrm{n})$ \\
\hline$-\phi^{-1}\left[-E T^{-1}\left[A s^{T}\right]+C s^{T}\right]$ & $(\mathrm{g})^{*}(\mathrm{~g})$ dense multiplication & $\mathrm{O}\left(\mathrm{g}^{2}\right)$ \\
\hline \multicolumn{3}{|c|}{ p2 Complexity } \\
\hline Operation & Requirements & Complexity \\
\hline$A s^{T}$ & $(\mathrm{~m}-\mathrm{g})^{*}(\mathrm{n}-\mathrm{m})$ sparse multiplication & $\mathrm{O}(\mathrm{n})$ \\
\hline$B p_{1}^{T}$ & $(\mathrm{~m}-\mathrm{g})^{*} \mathrm{x}(\mathrm{g})$ sparse multiplication & $\mathrm{O}(\mathrm{n})$ \\
\hline$A s^{T}+B p_{1}^{T}$ & (m-g) bit addition & $\mathrm{O}(\mathrm{n})$ \\
\hline$-T^{-1}\left[A s^{T}+B p_{1}{ }^{T}\right]$ & $(\mathrm{m}-\mathrm{g})^{*}(\mathrm{~m}-\mathrm{g})$ back subtraction & $\mathrm{O}(\mathrm{n})$ \\
\hline
\end{tabular}

Table 3. p1 and p2 computational complexity 
International Journal of VLSI design \& Communication Systems (VLSICS) Vol.7, No.5/6, December 2016

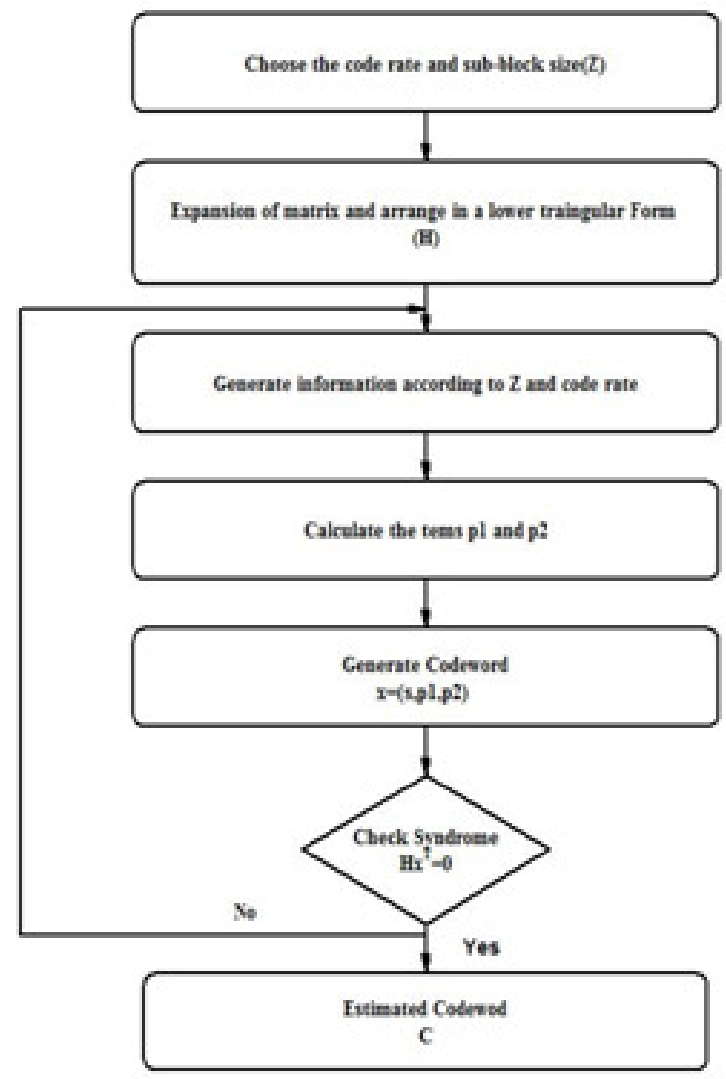

Figure 4, Flow chart of Encoding Process

The inverse of the matrix in the equation of $\mathrm{p}_{1}{ }^{\mathrm{T}}$ is not a sparse matrix, thus the computational complexity of the encoder is high. The LDPC decoder operates in linear time, hence it may be difficult to perform low-complexity encoding of these codes [11]. S. Myung et al. , in their paper proposed an encoding algorithm for LDPC codes with linearly scaled complexity, based on the principal to choose the matrix $\varphi$ as the identity matrix or a circulant permutation matrix [26].The encoding procedure of Block-LDPCs is simplified and summarized in equation 10-14 as follows[5].

\section{Simplified Encoding Steps :}

Step1: Calculate

Step2: Calculate

Step3: Calculate

Step4: Calculate

Step5: Calculate Codeword

$$
A s^{T} \text { and } C s^{T}
$$$$
E T^{-1} A s^{T}
$$$$
p_{1}^{T}=E T^{-1} A s^{T}+C s^{T}
$$$$
T p_{2}{ }^{T}=A s^{T}+B p_{1}{ }^{T}
$$$$
x=\left[s, p_{1}^{T}, p_{2}{ }^{T}\right]
$$

Where $\mathrm{s}$ are message bits and $\mathrm{p}_{1}, \mathrm{p}_{2}$ are parity bits. 
International Journal of VLSI design \& Communication Systems (VLSICS) Vol.7, No.5/6, December 2016

\section{LOW-DEnSITY PARITY CHECK CODES ENCODER ARCHITECTURE}

In this section we describe a hard-wired methodology for implementing QC-LDPC encoder architecture based on Richardson - Urbanke encoding method for the IEEE 802.11n standard with $1 / 2$ code rate, 648 coward length and sub-block size $\mathrm{z}=27$. In many QC LDPC encoder designs hard-wired in the LUTs, cycles-shifters and block-memories conventionally are used. In the present work, all these are eliminated, which result in the hardware optimization and high throughput [10]. This work focuses on the reduction of hardware multiplication by constant binary matrices. Fig.5 describes an architecture of the QC-LDPC encoder for the IEEE 802.11n standard $($ Rate $=1 / 2$ and sub-block size $\mathrm{z}=27$ ).

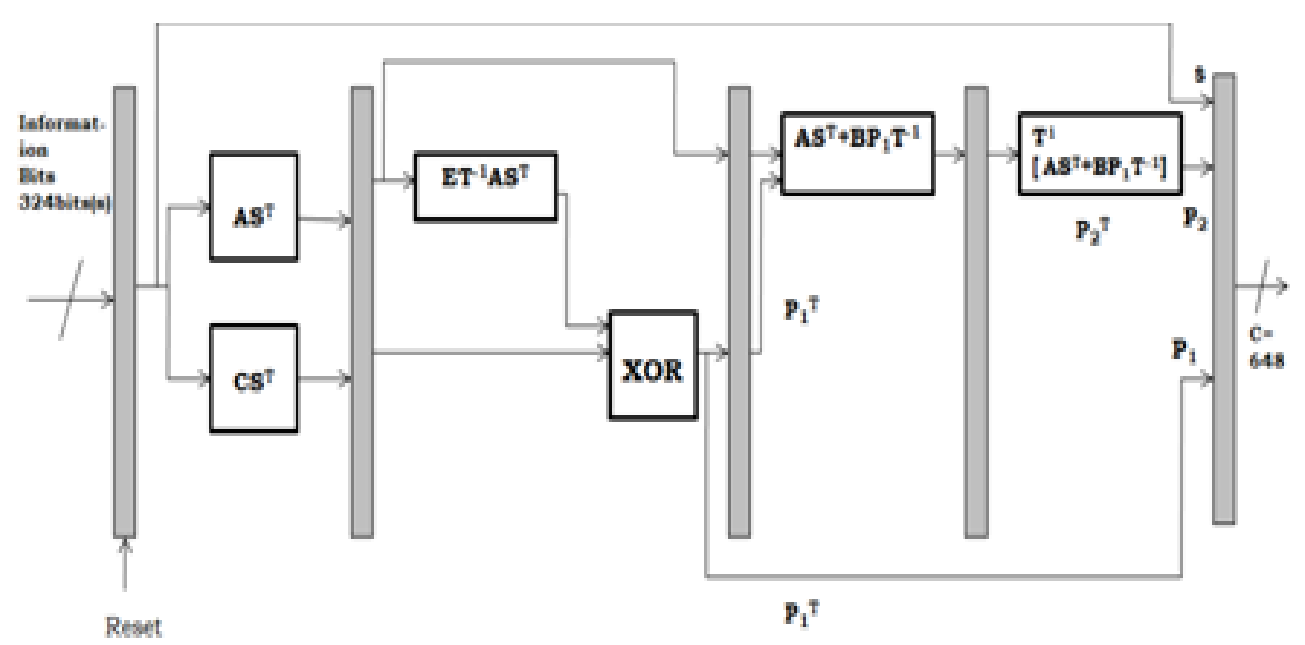

Figure 5. Architecture of the QC-LDPC encoder for the IEEE 802.11n standard (Rate $=1 / 2$ and sub-block size $\mathrm{z}=27$ )

In the above architecture the arithmetic operations of the binary LDPC codes are in GF (2) (i.e.modulo-2 addition). Hence XOR operators are used for all the generated blocks in the given architecture. Number of LUTS required for implementation of each block is not fixed. The proposed architecture shows that there is no need of block memories and there is a usable of a smaller number of gate results in a low complexity hardware.

\section{RESULTS AND DISCUSSION}

Most of the wireless communication standards described their parity-check matrix (PCM) in quasi-cyclic low-density parity-check (QC-LDPC) form. A Block-structured PCM for IEEE802.11, $\mathrm{N}=648$ bits, and $\mathrm{R}=1 / 2$ is constructed using an identity sub-matrix which is rotated or shifted by an amount specified by a shift matrix is shown in Fig.6. 


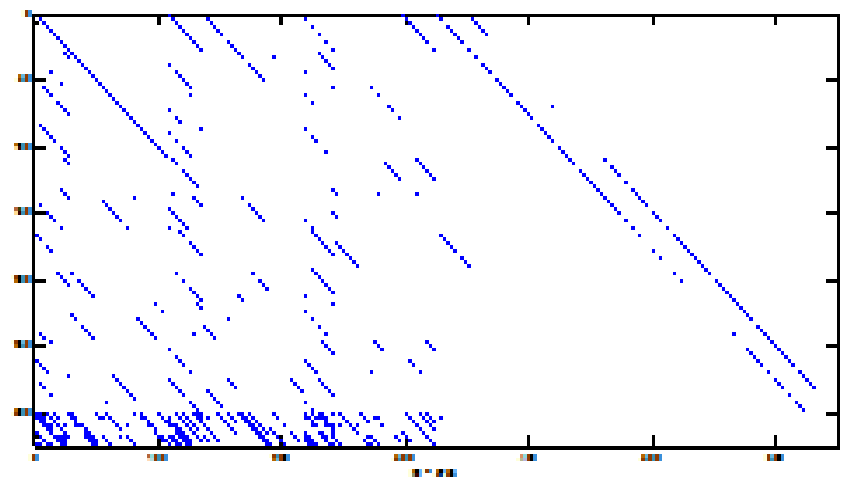

Figure 6. An IEEE $802.11 \mathrm{n}$ rate $1 / 2,648$ code length QC-LDPC parity check matrix

The proposed encoder architectures have been implemented in hardware for IEEE 802.11 QCLDPC defined by the parity- check matrix given by the standard for codeword length $\mathrm{n}=648$ bits, rate $1 / 2$ and block size $\mathrm{z}=27$. Table IV lists the corresponding occupied area in the Xilinx Virtex-5 FPGA device xc5vlx110t-1ff1136. The proposed rate QC-LDPC encoder can support up to $12.12 \mathrm{Gbps}$ throughput at $301.433 \mathrm{MHz}$ clock frequency.

Table 4: Resource consumption of proposed encoder in Xilinx Virtex-5 FPGA

\begin{tabular}{|c|c|c|}
\hline Resource & Number & Usage Rate \\
\hline Number of slice registers & 2906 & $4 \%$ \\
\hline $\begin{array}{c}\text { Number of slice LUTs } \\
\text { Fumber of Fully used LUT- }\end{array}$ & 1335 & $1 \%$ \\
\hline Number of bonded IOBs & 64 & $37 \%$ \\
\hline Number of BUFG/BUFGCTRLs & 1 & $10 \%$ \\
\hline
\end{tabular}

Table 5. lists Comparison of the existing LDPC encoder for wireless IEEE 802.11n with proposed architecture. The comparison shows that as we avoid cyclic shifters, block memories that are used in conventional encoders and apply hardwired method leads to high encoding speed, significantly higher throughput. As far no barrel shifters are used proposed architecture is less complex and area efficient

Encoders in the literature survey are implemented using different technologies and FPGA devices. These are applied for different codes and applications. Hence complexity and performance are not directly comparable. Table VI summarizes Comparison of proposed LDPC encoders with reported works stating several encoding parameters. Aaron E. Cohen, Keshab K. Parhi design encoders for a 10-Gigabit Ethernet transceiver which is compliant with the IEEE 802.3an standard using Hybrid (G -Matrix method and RU) method. They apply hybrid method on the RS $(2048,1723)$ LDPC codes.A new Hybrid LDPC encoder is compared with existing known methods $\mathrm{G}$ matrix multiplication and the RU method in terms of area, critical path, and power consumption[9]. Zhuo Ma et al. proposes a bidirectional recursion arithmetic method a 
International Journal of VLSI design \& Communication Systems (VLSICS) Vol.7, No.5/6, December 2016

quasi-parallel LDPC encoder code in IEEE 802.16e. This method reduces the encoding complexity and improves the coding efficiency. The encoder design for half rate LDPC code with code length 2304 can work at 50MHz[12]. Zhibin Zeng applies LU decomposition with dynamic programming for LDPC encoder for CMMB. For the $1 / 2$ code rate, encoder work at.

Table 5. Comparison of LDPC encoder for wireless IEEE 802.11n.

\begin{tabular}{|c|c|c|c|c|c|c|c|c|c|c|}
\hline Work & $\begin{array}{l}\text { Code } \\
\text { rate }\end{array}$ & $\begin{array}{l}\text { Code } \\
\text { word } \\
\text { length }\end{array}$ & FFs & $\begin{array}{l}\text { XOR } \\
\text { Gates }\end{array}$ & $\begin{array}{l}\text { Barrel } \\
\text { shifter }\end{array}$ & $\begin{array}{l}\text { 2nd- } \\
\text { stage } \\
\text { cyclic } \\
\text { shifter }\end{array}$ & $\begin{array}{l}\text { Clock } \\
\text { cycles }\end{array}$ & $\begin{array}{l}\text { Block - } \\
\text { memories }\end{array}$ & $\begin{array}{l}\text { Target } \\
\text { device }\end{array}$ & Frequency \\
\hline [16] & $1 / 2$ & 1296 & 1701 & 1620 & 20 & - & 24 & $\sqrt{ }$ & $\begin{array}{l}\text { Spartan } \\
-3\end{array}$ & - \\
\hline [17] & $1 / 2$ & 1296 & 162 & 243 & 1 & - & $73-83$ & $\sqrt{ }$ & $\begin{array}{l}\text { Spartan } \\
-3\end{array}$ & - \\
\hline [18] & $5 / 6$ & 1944 & 1053 & 1053 & 1 & 11 & 24 & $\sqrt{ }$ & - & - \\
\hline [5] & $5 / 6$ & 1944 & 2187 & - & - & - & 4 & $\mathrm{x}$ & Virtex 5 & $290 \mathrm{MHZ}$ \\
\hline [21] & $1 / 2$ & 648 & - & - & 22 & - & 21 & $\sqrt{ }$ & ASIC & $100 \mathrm{MHz}$ \\
\hline Proposed & $1 / 2$ & 648 & 1164 & - & - & - & 4 & $\mathrm{x}$ & $\begin{array}{l}\text { Virtex- } \\
5\end{array}$ & $\begin{array}{l}301.433 \mathrm{M} \\
\mathrm{Hz}\end{array}$ \\
\hline
\end{tabular}

maximum frequency $200 \mathrm{MHz}$, system pure encoding achieves $54 \mathrm{Mbps}$ throughput and $86 \mathrm{Mbps}$ for 3/4 code rate [13]. Ale Aldin AL Hariri, Fabrice Monteiro et.al. design LDPC encoder for a length of 64800 bits and the code rate of 5/6 were used for DVBS2, whereas for DVB-T2 block length of 16200 bits and code rate of 7/9 [14]. They also proposed Configurable and Highthroughput Architectures for Quasi-Cyclic Low-Density Parity-Check encoder for the WiMAX (IEEE 802.16e) and the WiFi (IEEE 802.1 In) protocols. Throughput up to $32 \mathrm{Gbits} / \mathrm{s}$ have been achieved for the encoder [22]. Silvia Anggraeni et al.use bit-wise matrix-vector Multiplication method for proposed encoder applied to IEEE 802.16e. The architecture works in terms of information throughput ranging from 0.235 to 8.83 times higher than other works [15]. Sunitha Kopparthi and Don M. Gruenbacher design LDPC encoder for IEEE 802.16e standard. The encoder design presented has a significantly high throughput of 422 Mbps.[19]. Hemesh Yasotharan et.al present encoder that simplifies the calculations found in other flexible encoders results in increasing memory usage also parallelization and faster encoding .The encoder had a throughput between 115Mbps and 360Mbps depending upon the code rate and block length[20] 
International Journal of VLSI design \& Communication Systems (VLSICS) Vol.7, No.5/6, December 2016

Table 6. Comparison of proposed LDPC encoders with Existing works

\begin{tabular}{|c|c|c|c|c|c|c|c|c|c|c|c|c|}
\hline \multirow[b]{2}{*}{ Work } & \multicolumn{2}{|c|}{\begin{tabular}{|c|} 
Panity check \\
matrix \\
structure \\
\end{tabular}} & \multicolumn{3}{|c|}{$\begin{array}{c}\text { Type of } \\
\text { Architecture }\end{array}$} & \multirow{2}{*}{$\begin{array}{l}\text { Applicati } \\
\text { on } \\
\text { standard }\end{array}$} & \multirow[b]{2}{*}{$\begin{array}{l}\text { Encoding } \\
\text { Algorithm }\end{array}$} & \multirow{2}{*}{$\begin{array}{c}\text { Code } \\
\text { lengt } \\
\mathrm{h}\end{array}$} & \multirow{2}{*}{$\begin{array}{c}\text { Cod } \\
\text { e } \\
\text { rate }\end{array}$} & \multirow[b]{2}{*}{ Frequency } & \multirow[b]{2}{*}{$\begin{array}{c}\text { Through } \\
\text { put }\end{array}$} & \multirow[b]{2}{*}{ Technology } \\
\hline & $\begin{array}{c}\text { QC/str } \\
\text { uct }\end{array}$ & $\begin{array}{c}\text { Non } \\
- \\
\text { stru } \\
\text { ct }\end{array}$ & $\begin{array}{c}\text { Seri } \\
\text { al }\end{array}$ & $\begin{array}{c}\text { Partia } \\
1 \\
\text { Parall } \\
\text { el }\end{array}$ & $\begin{array}{c}\text { Fully- } \\
\text { Parall } \\
\text { el }\end{array}$ & & & & & & & \\
\hline [9] & $\sqrt{ }$ & & & & $\sqrt{ }$ & $\begin{array}{c}\text { IEEE } \\
802.3 \text { an } \\
\text { (10GBas } \\
\mathrm{e}-\mathrm{T} \\
\text { ethernet) }\end{array}$ & \begin{tabular}{|c} 
hybrid \\
encoding/ \\
$\mathrm{G}$ \\
matrix \\
multiplicati \\
on method.
\end{tabular} & $\begin{array}{c}2048 \\
- \\
1723\end{array}$ & - & - & $\begin{array}{c}\text { High(Gb } \\
\text { ps) }\end{array}$ & $\begin{array}{c}\text { Xilinx Virtex } 4 \\
\text { (xc4vlx25- } \\
12 \text { sf363 }\end{array}$ \\
\hline [12] & $\sqrt{ }$ & & & & $\sqrt{ }$ & $\begin{array}{c}\text { IEEE } \\
802.16 e\end{array}$ & \begin{tabular}{|c|} 
bidirection \\
al recursion \\
encoding
\end{tabular} & 2304 & $1 / 2$ & & $50 \mathrm{Mb} / \mathrm{s}$. & $\begin{array}{c}\text { Xilinx's } \\
\text { XC3S1000 }\end{array}$ \\
\hline [13] & $\sqrt{ }$ & & & & $\sqrt{ }$ & CMMB & \begin{tabular}{|c|} 
LU \\
$\begin{array}{c}\text { decomposit } \\
\text { ion }\end{array}$
\end{tabular} & 4608 & $\begin{array}{l}1 / 2- \\
3 / 4\end{array}$ & $200 \mathrm{MHz}$ & $\begin{array}{l}54-86 \\
\text { Mbps }\end{array}$ & $\begin{array}{c}\text { Altera Stratix II } \\
\text { EP1S180F1020 } \\
14\end{array}$ \\
\hline [14] & $\sqrt{ }$ & & & $\sqrt{ }$ & & DVB-T2 & F.Sub & $\begin{array}{c}6480 \\
0 \\
1620 \\
0\end{array}$ & $\begin{array}{l}5 / 6- \\
7 / 9\end{array}$ & 328Mhz. & $\begin{array}{l}28.9 \\
\text { Gbps }\end{array}$ & $\begin{array}{c}\text { Altera Stratix } \\
\text { EP3SE50F484 } \\
\text { C2 device }\end{array}$ \\
\hline [15] & $\sqrt{ }$ & & & & $\sqrt{ }$ & $\begin{array}{c}\text { IEEE } \\
802.16 e\end{array}$ & $\begin{array}{c}\text { Bit-wise } \\
\text { matrix- } \\
\text { vector } \\
\text { multiplicati } \\
\text { on }\end{array}$ & 576 & $1 / 2$ & $\begin{array}{c}154.63 \mathrm{Mh} \\
\mathrm{z}\end{array}$ & $\begin{array}{l}4.948 \\
\text { Gbps }\end{array}$ & $\begin{array}{c}\text { Altera Stratix } \\
\text { EP1S80F1508 } \\
\text { C5 }\end{array}$ \\
\hline [19] & $\sqrt{ }$ & & & & $\sqrt{ }$ & $\begin{array}{c}\text { IEEE } \\
802.16 e\end{array}$ & $\begin{array}{c}\text { F.Sub.(dual } \\
\text { H2) }\end{array}$ & $\begin{array}{l}576- \\
2304\end{array}$ & \begin{tabular}{|l|}
$1 / 2$ \\
$2 / 3$ \\
$3 / 4$ \\
$5 / 6$ \\
\end{tabular} & $\begin{array}{l}422.12 \\
\text { MHz. }\end{array}$ & $\begin{array}{c}400 \\
\text { Mbps }\end{array}$ & Altera Stratix \\
\hline [20] & $\sqrt{ }$ & & & & $\sqrt{ }$ & $\begin{array}{c}\text { IEEE } \\
802.16 e\end{array}$ & $\begin{array}{l}\text { generator } \\
\text { matrix }\end{array}$ & $\begin{array}{c}2304 \\
\text { bits }\end{array}$ & $1 / 2$ & $60 \mathrm{MHz}$ & $\begin{array}{c}119 \\
\text { Mbpss }\end{array}$ & $\begin{array}{c}\text { Xilinx Virtex-II } \\
\text { XCV4000-6 } \\
\text { FPGA }\end{array}$ \\
\hline [21] & $\sqrt{ }$ & & & & $\sqrt{ }$ & $\begin{array}{c}\text { IEEE } \\
802.11 \mathrm{n}\end{array}$ & $\begin{array}{l}\text { Linear } \\
\text { Encoding }\end{array}$ & $\begin{array}{c}648 \\
1296 \\
1944\end{array}$ & \begin{tabular}{|l|}
$1 / 2$ \\
$2 / 3$ \\
$3 / 4$ \\
$5 / 6$
\end{tabular} & $100 \mathrm{MHz}$ & 7.7 Gbps & ASIC \\
\hline [22] & $\sqrt{ }$ & & & & $\sqrt{ }$ & $\begin{array}{l}\text { (IEHE } \\
802.16 e\end{array}$ & $\begin{array}{l}\text { Linear } \\
\text { Encoding }\end{array}$ & $\begin{array}{l}1152 \\
2304\end{array}$ & $1 / 2$ & $112 \mathrm{Mzs}$ & $\begin{array}{l}32832 \\
\text { Mbps }\end{array}$ & $\begin{array}{c}\text { Altera Stratix III } \\
\text { device } \\
\text { (EP3SE50F780 } \\
\text { C2). } \\
\end{array}$ \\
\hline [23] & $\sqrt{ }$ & & & & $\sqrt{ }$ & DVB-S2 & F.Sub & 360 & & $100 \mathrm{MHz}$ & $10 \mathrm{Gbps}$ & $\begin{array}{c}\text { Xilinx Vertex5- } \\
\text { LX155T }\end{array}$ \\
\hline$[24]$ & & $\sqrt{ }$ & & & $\sqrt{ }$ & CMMB & RU & & \begin{tabular}{|l|}
$1 / 2$ \\
and \\
$3 / 4)$ \\
\end{tabular} & $\begin{array}{c}200.23 \\
\mathrm{MHz}\end{array}$ & \begin{tabular}{|c|}
34 Mbps \\
and 69 \\
Mbps
\end{tabular} & \begin{tabular}{|c|} 
Altera Stratix II \\
EP1S180F1020 \\
14 \\
\end{tabular} \\
\hline [25] & $\sqrt{ }$ & & $\sqrt{ }$ & & & CMMB & \begin{tabular}{|c|} 
LU \\
$\begin{array}{c}\text { decomposit } \\
\text { ion }\end{array}$ \\
\end{tabular} & $\begin{array}{c}9219 \\
-\end{array}$ & $\begin{array}{l}1 / 2- \\
3 / 4\end{array}$ & $200 \mathrm{MHz}$ & $\begin{array}{l}32-67 \\
\text { Mbps }\end{array}$ & $\begin{array}{c}\text { Alsera Srarix II } \\
\text { EP2S90 }\end{array}$ \\
\hline $\begin{array}{l}\text { Propos } \\
\text { ed }\end{array}$ & $\sqrt{ }$ & & & & $\sqrt{ }$ & $\begin{array}{c}\text { IEEE } \\
802.11 \mathrm{n}\end{array}$ & RU & 648 & $1 / 2$ & $\begin{array}{c}301.433 \mathrm{M} \\
\mathrm{Hz}\end{array}$ & $\begin{array}{l}12.12 \\
\text { Gbps }\end{array}$ & \begin{tabular}{|c|} 
Xilinx Virtex-5 \\
xc5vix $110 \mathrm{t}-$ \\
1ff1136 \\
\end{tabular} \\
\hline
\end{tabular}

Yong-Min Jung et al. proposes a high-throughput encoder architecture for quasi-cyclic lowdensity parity-check codes in IEEE 802.11ac standard. It is implemented with 130-nm CMOS technology for LDPC $(1944,1620)$ irregular code which achieved 7.7 Gbps throughput at 100 $\mathrm{MHz}$ clock frequency[21]. InKi Lee et al. propose high-speed LDPC Encoder Architecture for Digital Video Broadcasting Systems. They used an efficient encoding method for DVB-S2 LDPC codes which is done without reference to the code generation matrices. This architecture results in maximum throughput is up to $10 \mathrm{Gbps}$ with a $100 \mathrm{MHz}$ clock[23]. 
International Journal of VLSI design \& Communication Systems (VLSICS) Vol.7, No.5/6, December 2016

Xiangran Sun, Zhibin Zeng, Zhanxin Yang design Low Complexity LDPC Encoder use Optimized RU Algorithm With Backtracking for CMMB. This encoder work at the maximum frequency is $200.23 \mathrm{MHz}$ achieve throughputs up to $34.12 \mathrm{Mbps}$ for $1 / 2$ code rate and 69.23 Mbps for 3/4 code rate [24]. Wang Peng, Chen Yong-en have proposed low-complexity real-time LDPC encoder design for CMMB based on the LU decomposition method. It shows Maximum frequency achieved is $200 \mathrm{MHz}$. Throughput ranges from $32.44 \mathrm{Mbps}$ for (1/2 code rate) and $67.16 \mathrm{Mbps}$ for $3 / 4$ code rate [25]. It is shown that the proposed architectures compare favourably to the other works in the sense of flexibility and complexity. The proposed architecture focuses Low complexity and high throughput for IEEE 802.11n standard.

\section{CONCLUSiOnS}

We have described RU encoding methodology for QC-LDPC codes for IEEE 802.11n standard with $1 / 2$ code rate, 648 codeword length, and sub-block size $\mathrm{z}=27$. The proposed encoder is found to be low complexity compared to previous encoder designs and allow efficient parallelism, flexibility, and high throughput rate. The hard-wire based encoder leads to high encoding speed and less resources utilization due to elimination cyclic shifters and block memories and utilization of multiplication by the constant binary matrix method. The proposed QC-LDPC encoder can support up to $12.12 \mathrm{Gbps}$ throughput at $301.433 \mathrm{MHz}$ clock frequency.

\section{ACKNOWLEDGMENT}

The author would like to thank Georgios Tzimpragos, Christoforos Kachris, Dimitrios Soudris and Ioannis Tomkos for simplified low complexity encoding algorithm of LDPC codes.

\section{REFERENCES}

[1] R. G. Gallager,(1962)'Low-density parity check codes.', IRE Transaction Info.Theory, Vol.8,No.1, pp 21-28.

[2] D. J. C. MacKay and R. M. Neal, (1996) "Near Shannon Limit Performance of Low Density ParityCheck Codes," Electronics Letters, Vol. 32 No. 18, pp. 1645-1646.

[3] Thomas J. Richardson and Rudiger L. Urbanke,( 2001) "Efficient encoding of low-density paritycheck codes.”, IEEE Transactions on Information Theory, Vol 47 No 2,pp. 638-656.

[4] Huxing Zhang, HongyangYu,"Multi-rate QC-LDPC Encoder.”, IEEE Circuits and Systems International Conference on Testing and Diagnosis , 2009, pp 1-4.

[5] Georgios Tzimpragos,Christoforos Kachris and Dimitrios Soudries "A low-complexity implementation of QC-LDPC encoder in reconfigurable logic.", International Conference on Field programmable Logic and Applications.; ,2013, pp 1-4.

[6] IEEE P802.11n/TM-2009, IEEE Standard for Information Technology Part 11: Wireless LAN Medium Access Control (MAC) and Physical Layer (PHY) specifications. 2001.

[7] IEEE 802.11acTM/D2.0., Draft Standard for Information Technology Part 11: Wireless LAN Medium Access Control (MAC) and Physical Layer (PHY) specifications, Amendment 4: Enhancements for Very High Throughput for Operation in Bands below 6GHz. 2013. 
International Journal of VLSI design \& Communication Systems (VLSICS) Vol.7, No.5/6, December 2016

[8] IEEE Std 802.16eTM-2005, IEEE Standard for Local and metropolitan area networks Part 16: Air Interface for Fixed and Mobile Broadband Wireless Access Systems.2006.

[9] AE Cohen, KK Parhi.., (2009)" A Low-Complexity Hybrid LDPC Code Encoder for IEEE 802.3an (10GBase-T) Ethernet"., IEEE TRANSACTIONS ON SIGNAL PROCESSING.,Vol.57,No.10,pp 4085 - 4094 .

[10] Georgios Tzimpragos,Christoforos Kachris and Dimitrios Soudries ,'Automatic Implementation of Low-Complexity QC-LDPC Encoders.", Workshop on Power and Timing Modeling, Optimization and Simulation (PATMOS),Sept. 2013,pp 243 - 246.

[11] Ahmad Mahdi , Nikos Kanistras and Vassilis Paliouras ," An encoding scheme and encoder architecture for rate-compatible QCLDPC codes." IEEE Workshop on Signal Processing Systems (SiPS), Oct.2011,pp 328-333.

[12] Zhuo Ma,Ying L and Xinmie Wang, "A Quasi-Parallel Encoder of Quasi-Cyclic LDPC Codes in IEEE 802.16e." International Conference on Information Science and Engineering ,Dec 2009,pp$2492-2495$.

[13] Zhibin Zeng ,"A High-efficiency LDPC Encoder for CMMB with Dynamic Programming. “,. International Conference on Intelligent Computation Technology and Automation (ICICTA). ,Mar 2011,pp 337- 340 .

[14] Alaa Aldin Al Hariri, Fabrice Monteiro and Loic Sieler.,"A High Throughput Configurable Parallel Encoder Architecture for Quasi-Cyclic Low-Density Parity-Check Codes.” IEEE 19th International On-Line Testing Symposium (IOLTS)., July 2013; pp163-166

[15] Silvia Anggraeni; Fawnizu Azmadi Hussin; Varun Jeoti,"High Throughput Architecture for Low Density Parity Check (LDPC) Encoder.”, IEEE 56th International Midwest Symposium on Circuits and Systems (MWSCAS) ., Aug 2013;pp- 948 - 951.

[16] Z. Cai, J. Hao, P.H. Tan, S. Sun and P.S. Chin, (2006.),"Efficient encoding of IEEE 802.11n LDPC.”; Electronics Letter.,Vol. 42 No. 25 ,pp 1471-1472.

[17] J.M. Perez, V. Fernandez, (2008) ,’Low-cost encoding of IEEE 802.11n.”, Electronics Letter., Vol. 44, No. 4, pp 307-308.

[18] Y. Jung., J. Kim ,(2010),’Memory-efficient and high-speed LDPC Encoder.”, Electronics Letter. , Vol. 46, No. 14 ,pp 1035-36.

[19] Sunitha Kopparthi , Don M. Gruenbacher," Implementation of a flexible encoder for structured lowdensity parity-check codes", IEEE Pacific Rim Conf. Commun., Comput. Signal Process. Aug 2007; pp-438-441.

[20] Hemesh Yasotharan, Anthony Chan Carusone,"A flexible hardware encoder for systematic lowdensity parity-check codes," IEEE Internatinal Midwest Symposium on Circuits System. (MWSCAS'09). ,Aug 2009; pp 54-57.

[21] Yong-Min Jung , Chul-Ho Chung , Yun-Ho Jung , and Jae-Seok Kim ., (2014) '7.7 Gbps Encoder Design for IEEE 802.11ac QC-LDPC codes.', JOURNAL OF SEMICONDUCTOR TECHNOLOGY AND SCIENCE, VOL.14, NO.4, pp 419-425. 
International Journal of VLSI design \& Communication Systems (VLSICS) Vol.7, No.5/6, December 2016

[22] Alaa Aldin Al Hariri, Fabrice Monteiro, Loic Sieler and Abbas Dandache"Configurable and HighThroughput Architectures for Quasi-Cyclic Low-Density Parity-Check Codes.”, IEEE International Conference on Electronics, Circuits and Systems (ICECS).,Dec 2014,pp 790-793.

[23] InKi Lee, DeockGil Oh, MinHyuk Kim, JiWon Jung ,"High-speed LDPC Encoder Architecture for Digital Video Broadcasting Systems" International Conference on ICT Convergence (ICTC).,Oct 2013,pp 606-607.

[24] Xiangron Sun, Zhibin Zeng, Zhanxin Yang.” A Novel Low Complexity LDPC Encoder Based On Optimized RU Algorithm With Backtracking",. International Conference on Multimedia Technology (ICMT).,Oct 2010,pp1-4.

[25] WANG PENG, CHEN YONG-EN," LOW-COMPLEXITY REAL-TIME LDPC ENCODER DESIGN FOR CMMB." ,, INTERNATIONAL CONFERENCE ON INTELLIGENT INFORMATIO N HIDING MULTIMEDIA SIGNAL PROCESS. ,AUG 2008; PP-1209-1212.

[26] Seho Myung, Kyeongcheol Yang, and Jaeyoel Kim,(2005) "Quasi-cyclic ldpc codes for fast encoding.”, IEEE Transactions on Information Theory,Vol.51, No.8,pp 2894-2901.

[27] Yi Hua Chen, Jue Hsuan Hsiao, Zong Yi Siao, "Wi-Fi LDPC Encoder with Approximate Lower Triangular Diverse Implementation and. Verification”, 'International Multi-Conference on Systems, Signals \& Devices (SSD). ,Feb 2014,pp1-6.

\section{AUTHORS}

Monica Mankar received M. Tech degree in Electronics Engineering from RTMNU Nagpur in 2008. Currently she is pursuing PhD from RTMNU Nagpur.She is presently working as Assistant Professor in Electronics Engineering in Yeshwantrao Chavan college of Engg, Nagpur, India Her areas of interest are communication and VLSI Design. She is a lifetime member of ISTE . She is having total 11 years of teaching experience .

Gajendra Asutkar received the Master in Technology Degree in Power Electronics Engineering from Visvesvaraya Technological University, Belgaum (India) in the year 2001. Currently he is pursuing $\mathrm{PhD}$ from Visvesvaraya National Institute of Technology, Nagpur (VNIT) (India).His research contributions Encompass broad aspects of wireless communications and networking \& Image Processing. He is presently working as a Professor in Electronics \& Communication Engineering Department, Priyadarshani Institute of Engineering and technology, Nagpur (India). His professional society's

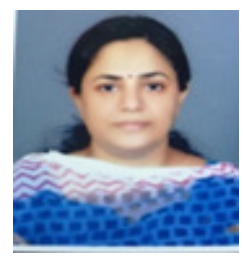
affiliation includes Student Member IEEE, LM-ISTE, and LM-CSI. He has worked as Reviewer for many technical research papers for International Conferences \& has also chaired the session. He has 33 research publications to his credit in various conferences including referred international conference

Pravin Dakhole was born in India. He received M. Tech degree in Electronics Engineering from VNIT, Nagpur in 1999 and the Ph. D degree from Sant Gadge Baba Amravati University, Amravati in 2010. He is presently working as Professor in Electronics Engineering \& Registrar in Yeshwantrao Chavan college of Engg, Nagpur ,India . His areas of interest are front end \& back end VLSI Design. He is trainer to corporate / industries in the field of Verification of HDL based design. He is recipient of

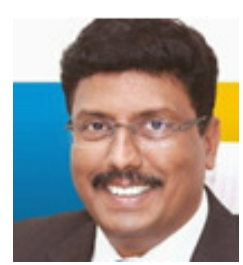
Best paper Award \& Best Teacher Award. Currently he is Senate member at RTM Nagpur University. He is a senior Fellow member of IEEE. He is having total 25 years of teaching experience with two years industrial experience. He is having more than 50 research paper publication. 